\title{
Exposure of Skin Homografts from Related Living Donors to Radiotherapy and Its Effects on Acute Rejection and Wound Healing in Children with Deep Burns: A Randomized Controlled Trial
}

\author{
Mohammed Ahmed Megahed ${ }^{1}$ Sherief Mohamed El Kashty ${ }^{1} \quad$ Ahmed Tharwat Nassar $^{1}$ \\ Mohamed Aboulfetouh ${ }^{2}$ Mohammed Saad AboShaban ${ }^{10}$ \\ ${ }^{1}$ Plastic and Reconstructive Surgery Department, Faculty of Medicine, \\ Menoufia University, Shebin Elkom, Egypt \\ 2 Menoufia Cancer Institute, Clinical Oncology Department, Faculty of \\ Medicine, Menoufia University, Shebin Elkom, Egypt \\ Address for correspondence Mohammed Saad AboShaban, MD, Plastic \\ and Reconstructive Surgery Department, Faculty of Medicine, Menoufia \\ University, Yassein Abdelafar Street, Shebin Elkom 32511, Egypt \\ (e-mail: d.mohsaad@yahoo.com).
}

Indian J Plast Surg 2022;55:81-86.

\begin{abstract}
Background The ideal skin substitute should be more similar to normal skin function while causing fewer reactions. The purpose of this study was to assess the effect of radiotherapy on minimizing acute rejection and enhancing wound healing in children with deep burns.

Patients and Methods A prospective randomized control study included 34 children admitted to the burn unit with deep burns under the age of 12 years. Through the tomotherapy device, a skin homograft from a related living donor was exposed to a local dose of radiotherapy of 500 centigray (cGy). It was immediately used for coverage of the prepared bed after the irradiation was completed.

Results The mean values of the laboratory parameters (ESR, CRP, IL-6, and TNF) for all burn patients in the study showed a significant difference, with $p<0.001$. The mean \pm standard deviation (SD) of the time from homograft coverage to the appear-

\section{Keywords}

- burn

- deep

- children

- homograft

- radiotherapy

- rejection ance of rejection was $9.62 \pm 1.45$ in group 1 and $14.35 \pm 2.8$ in group 2 , with $p<0.001$ (highly significant difference), indicating that exposure to radiotherapy can reduce graft rejection.

Conclusions The exposure of skin homografts from related living donors to a local low dose of radiotherapy can reduce a graft's ability to initiate inflammatory and immunological reactions, thereby minimizing rejection of a graft and enhancing epithelialization in children with deep second- and third-degree burns.
\end{abstract}

published online

February 25, 2022
DOI https://doi.org/ 10.1055/s-0041-1740077. ISSN 0970-0358. (c) 2022. Association of Plastic Surgeons of India. All rights reserved. This is an open access article published by Thieme under the terms of the Creative Commons Attribution-NonDerivative-NonCommercial-License, permitting copying and reproduction so long as the original work is given appropriate credit. Contents may not be used for commercial purposes, or adapted, remixed, transformed or built upon. (https://creativecommons.org/ licenses/by-nc-nd/4.0/)

Thieme Medical and Scientific Publishers Pvt. Ltd., A-12, 2nd Floor, Sector 2, Noida-201301 UP, India 


\section{Introduction}

Extensive burns destroy the skin, ${ }^{1,2}$ lead to the release of proinflammatory mediators at the injury site, ${ }^{3,4}$ and cause the malfunction of microcirculation., ${ }^{5,6}$ These systemic changes can affect multiple organs in the body ${ }^{4}$ in a reciprocating manner. ${ }^{5}$ Approximately $45.3 \%$ of burn patients develop multiple-organ dysfunction, which is the leading cause of death in children. ${ }^{6}$

Some limitations restrict the use of autografts with escharectomy for children, such as an unstable sensitive condition, a small body surface area, and difficulty in determining the depth of chemical and electrical burns. ${ }^{7}$ An ideal skin substitute should mimic normal skin functions while causing fewer reactions. ${ }^{8}$ The skin is protected by a large number of tissue-resident memory T-cells, which are recognized by the immune system and initiate antigen-antibody reactions. ${ }^{9}$ Circulating T-cells infiltrate inflammatory sites and produce epithelial immunity with local antigen presentation. ${ }^{10}$ As a result, to use skin homografts as a long-term substitute, ${ }^{11}$ multiple methods for delaying rejection have evolved, either through systemic or local procedures, in order to minimize inflammatory and immune reactions. ${ }^{12}$

In this study, we assess the ability of radiotherapy to minimize acute rejection and enhance wound healing in children with deep burns, using skin homografts from related living donors. Radiotherapy can weaken the skin cells' ability to produce immune and inflammatory reactions, thereby avoiding the complications of systemic immunosuppressive drugs.

\section{Patients and Methods}

We conducted this prospective randomized controlled trial on 34 children (age: below 12 years) who were admitted to our burn unit between January 2018 and May 2020. On admission, the total body surface area of the burn was calculated using Lund and Browder's chart, and the patients received resuscitation treatment, including airway securing, fluid replacement, warming, and supportive medication, until their general condition stabilized. Local burn care was routinely provided while adhering to aseptic precautions.

\section{Inclusion and Exclusion Criteria}

- The inclusion criteria of this study were as follows: children with intermediate, major, and deep secondand third-degree burns with eschar formation, necessitating escharectomy and wound coverage.

- The exclusion criteria of this study were as follows: children with first-degree and superficial burns that appeared to be healing conservatively without requiring surgical intervention.

\section{Study Groups}

This study had the following two patient groups:

- Group 1 (control, nonexposed) included 17 patients with a skin homograft that was not exposed to radiotherapy.
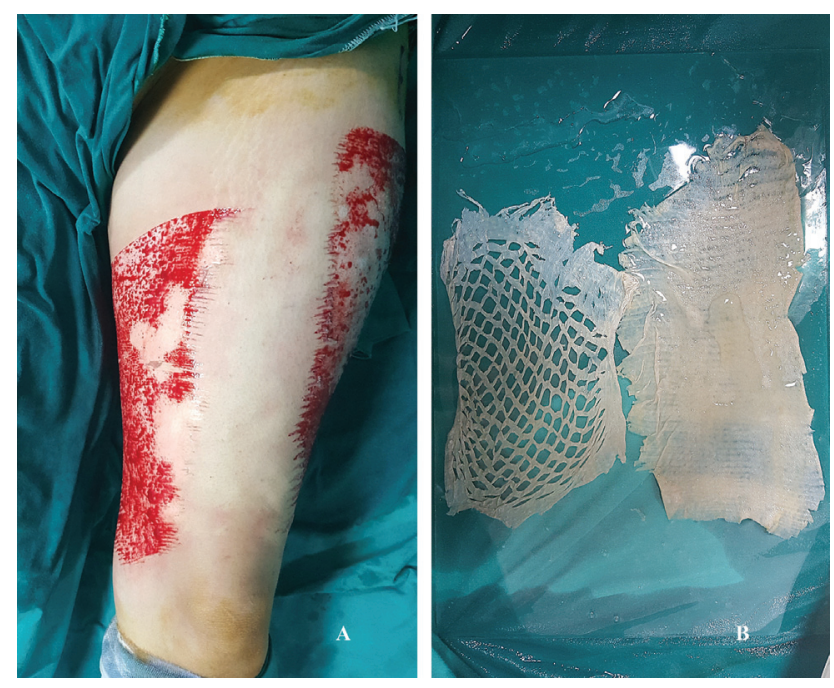

Fig. 1 Homograft preparation. (A) The graft was harvested from the thigh donor site with medium-sized split thickness. (B) Meshing of graft and socking by garamycin ampoule.

- Group 2 (case, exposed) included 17 patients in which the skin homograft was exposed to local radiotherapy (single, low dose of 500 centigray [cGy]) before application to the burn wound.

\section{Homograft Source and Preparation}

Patients in both the groups received skin homografts from living first-degree relatives (i.e., father, mother, brother, or sister). All donors provided written consent to donate their skin after a thorough discussion on all procedural steps and the anticipated time for donor site healing. The thigh was the preferred donor site for homografts, and medium-sized splitthickness grafts were harvested and applied on a sterile glass plate soaked with gentamicin solution (-Fig. 1).

\section{Local Radiotherapy}

Inside the tomotherapy unit for radiation, a calibrated dosimetric system consisting of an electrometer and an ionization chamber (M23332, Safe Work Permit process) was used. Beams were delivered using an automated system that moved the phantom at an $11 \mathrm{~cm}^{2}$ pencil beam in a homogenous-slice rotating attitude (-Fig. 2 ).

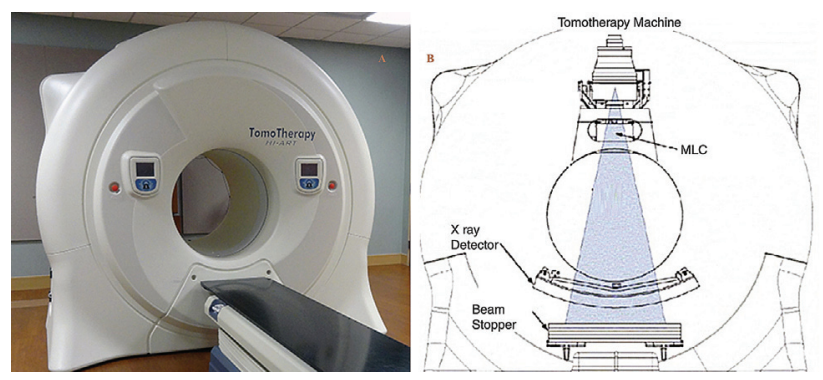

Fig. 2 Irradiation device. (A) The tomotherapy device with a calibrated dosimetric system, consisting of an electrometer and an ionization chamber (M23332, PTW). (B) The beams moving a phantom at a $1 \times 1 \mathrm{~cm}^{2}$ pencil beam in homogenous slice-rotate attitude by means of an automated system. 
The skin homograft was exposed to a low dose of radiation, $500 \mathrm{cGy}$, and the delivery process was replicated only once on the graft. The homograft was immediately used for the coverage of a prepared bed after irradiation was completed.

\section{Operative Procedures for Recipient Patients}

Under general anesthesia, the burn area was sterilized and escharectomy was performed, followed by immediate wound coverage with a nonexposed skin homograft for patients in group 1 or an irradiated homograft for patients in group 2. Next, fixation was performed with bulking dressing and tie-over sutures.

\section{Follow-Up}

To detect differences in the results between the two groups, the following data were collected before and after surgery and compared:

- Laboratory parameters such as the levels of C-reactive protein (CRP), erythrocyte sedimentation rate (ESR), interleukin 6 (IL-6), and tumor necrosis factor (TNF) were measured.

- Time elapsed between homograft coverage and the onset of rejection.

- Percentage of the area requiring an autograft application.

\section{Statistical Analysis}

To evaluate the differences between the two groups, we measured various parameters using one-way analysis of variance and posthoc Tukey's honest significant difference test. For statistical analyses, we used the Prism 5 software (GraphPad Software, San Diego, CA USA). We considered $p<0.001$ as highly statistically significant and $p<0.05$ as statistically significant.

\section{Results}

Group 1consisted of 17 patients ( 6 females and 11 males) with a mean age of 8.33 years (range: $1-12$ years) and a mean percentage of burns of $32.2 \%$. Group 2 included 17 patients ( 4 females and 13 males) with a mean age of 9.5 years (range: 212 years) and a mean percentage of burns of $28.37 \%$.

The average percentage of homografts harvested from donors was $8.9 \%$ (range: 7.5-9.0\%), with a 10.6-day healing period (range: 8-13 days). Donor site complications included delayed wound healing in two cases, wound infection, and hyperpigmentation in one case, all of which were treated conservatively.

The mean values of the laboratory parameters (ESR, CRP, IL-6, and TNF) for all burn patients in the study showed a significant difference, with $p<0.001$ ( - Table 1 ). This finding demonstrates a significant decrease in values for graft radiotherapy, indicating minimal inflammatory and immune reactions.

The mean \pm standard deviation (SD) of the time from homograft coverage to the appearance of rejection was $9.62 \pm 1.45$ in group 1 and $14.35 \pm 2.8$ in group 2, with $p<0.001$ (highly significant difference), indicating that exposure to radiotherapy can reduce graft rejection.

The number of patients who required an additional autograft application was 15 in group 1 (84.6\%) and 13 in group 2 (63.6\%), with $p>0.05$ (nonsignificant). The mean $\pm S D$ of the area requiring graft application was $88.5 \pm 14.33$ in group 1 and $62.7 \pm 12.55$ in group 2 (highly significant), indicating a significant effect of the irradiated homograft on decreasing the burn areas requiring a graft and also decreasing the percentage of graft taken from the patient with a good stability and fewer complications.

Table 1 Changes in the level of the following laboratory parameters including ESR, CRP, IL-6, and TNF before and after the surgery

\begin{tabular}{|c|c|c|c|c|c|}
\hline & $\begin{array}{l}\text { Group I homograft } \\
\text { not exposed to radiation } \\
n=17\end{array}$ & $\begin{array}{l}\text { Group II exposed } \\
\text { homograft to local radiation } \\
n=17\end{array}$ & $\mathrm{~T}$ test & $p$-Value \\
\hline & & Mean \pm SD & Mean \pm SD & & \\
\hline \multirow[t]{3}{*}{$\mathrm{ESR} / \mathrm{mm} / \mathrm{hr}$} & Before surgery & $49.437 \pm 11.684$ & $43.333 \pm 10.543$ & 2.853 & $>0.05$ \\
\hline & After surgery & $38.633 \pm 4.819$ & $13.543 \pm 4.879$ & 11.808 & 0.001 \\
\hline & $p$-Value & $<0.05$ & $0.001>$ & & \\
\hline \multirow[t]{3}{*}{ CRP $\mathrm{mg} / \mathrm{dl}$} & Before surgery & $51.617 \pm 6.491$ & $53.637 \pm 5.381$ & 3.906 & $>0.05$ \\
\hline & After surgery & $38.143 \pm 6.62$ & $11.100 \pm 3.632$ & 13.341 & $0.001>$ \\
\hline & $p$-Value & $<0.05$ & $0.001>$ & & \\
\hline \multirow[t]{3}{*}{ IL-6 } & Before surgery & $111.55 \pm 55.114$ & $120.82 \pm 70.14$ & 1.675 & $>0.05$ \\
\hline & After surgery & $68.550 \pm 48.43$ & $18.47 \pm 30.35$ & .987 & $0.001>$ \\
\hline & $p$-Value & $<0.05$ & $0.001>$ & & \\
\hline \multirow[t]{3}{*}{ TNF } & Before surgery & $44.87 \pm 15.55$ & $39.64 \pm 9.55$ & 3.67 & $>0.05$ \\
\hline & After surgery & $33.80 \pm 8.56$ & $18.832 \pm 7.62$ & 1.80 & $0.001>$ \\
\hline & $p$-Value & $<0.05$ & $0.001>$ & & \\
\hline
\end{tabular}

Abbreviations: CRP, C-reactive protein; ESR, erythrocyte sedimentation rate; IL-6, interleukin-6; SD, standard deviation; TNF, tumor necrosis factor. 
84 Skin Homograft Rejection in Deep Burned Children Megahed et al.

Table 2 The statistical difference between two groups regarding clinical outcomes

\begin{tabular}{|c|c|c|c|c|}
\hline & $\begin{array}{l}\text { Group I } \\
n=17 \\
\text { Mean } \pm \text { SD }\end{array}$ & $\begin{array}{l}\text { Group II } \\
n=17 \\
\text { Mean } \pm \text { SD }\end{array}$ & Test & $p$-Value \\
\hline $\begin{array}{l}\text { Hospital stay duration } \\
\text { (Mean } \pm \text { SD) }\end{array}$ & $31.3 \pm 5.09$ & $21.0 \pm 6.05$ & $\mathrm{~T}=8.341$ & $<0.001$ \\
\hline Patients number that needs another autograft: & & & \multirow[t]{3}{*}{$X^{2}=1.097$} & \multirow[t]{3}{*}{$>0.05$} \\
\hline Yes & $15(84.6 \%)$ & $13(63.6 \%)$ & & \\
\hline No & $2(15,4 \%)$ & $4(36,4 \%)$ & & \\
\hline $\begin{array}{l}\text { The period from homograft coverage to rejection } \\
\text { started (mean } \pm \text { SD) }\end{array}$ & $9.62 \pm 1.45$ & $14.35 \pm 2.8$ & $\mathrm{~T}=7.901$ & $<0.001$ \\
\hline Percentage of the area need autograft application (mean \pm SD) & $88.5 \pm 14.33$ & $62.7 \pm 12.55$ & $\mathrm{~T}=10.897$ & $<0.001$ \\
\hline
\end{tabular}

Abbreviations: SD, standard deviation.

We found a difference in hospital stay duration between groups 1 and 2, with a mean of 31.3 and 21.0 days, respectively. Irradiation reduces immune reactions and the possibility of eschar tissue formation, resulting in the acceleration of wound epithelialization which reduces hospital stay duration and morbidity (-Table $\mathbf{2}$ ).

\section{Discussion}

Many children with deep burns die because of a lack of autologous skin; thus, quick application of skin substitutes with minimal immune and inflammatory reactions is a major concern. Homografts are commonly used for coverage of raw burned areas.

No legal issues exist for the use of cadaveric skin grafts in developing countries that have limited skin-banking equipment. In this study, we used skin homografts harvested from living first-degree relatives with exposure to radiation therapy for inhibiting the ability of skin cell recognition, in order to stimulate the immune system, thereby reducing graft rejection and enhancing epithelialization. This method allows local exposure while avoiding systemic side effects and complications associated with immunosuppressive drugs.

Bhatia et $\mathrm{al}^{13}$ used homografts for neonates with burns with no donor sites and achieved satisfactory results. Although systemic immunosuppressive drugs can reduce rejection of organ transplants, such as kidneys, they have little or no effects on skin transplantation. ${ }^{11}$ Better healing and epithelialization occurs when the homograft rejection process is reduced by minimizing the immune system response. $^{14}$

According to Cheuk et al, topical suppression of epidermal memory cells can inhibit episodes of inflammation in certain dermatological diseases. ${ }^{15}$ Sterilization of grafts by irradiation is widely used and can provide less-expensive materials for treatment. ${ }^{16,17}$ Camacho and Guerrero recognized chemical and physical changes that influence the biological properties of a graft after exposure to radiation as a method of sterilization. ${ }^{18}$ Mahdavi-Mazdeh et al discovered significant results from clinical evaluations of patients with deep skin
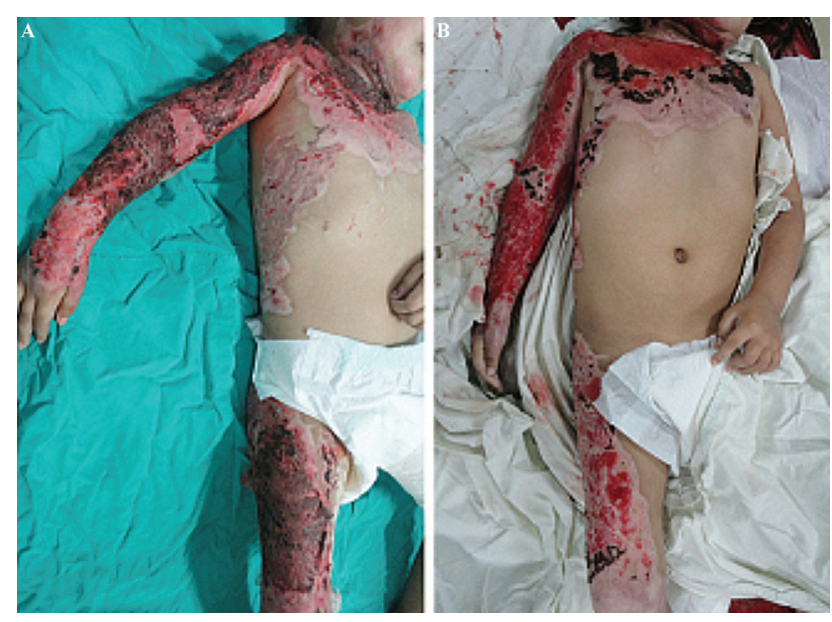

Fig. 3 Female patient, 4 years old, with scald deep dermal burn. (A) Early escharectomy and coverage with nonirradiated skin homograft from father was done. The chest show area of epithelization and healing after 13 days from coverage. (B) Rejection of homograft was completed after 15 days from homograft coverage with a ready granulated bed for autograft replacement. The percentage of rejection was about $80 \%$ of burned area.
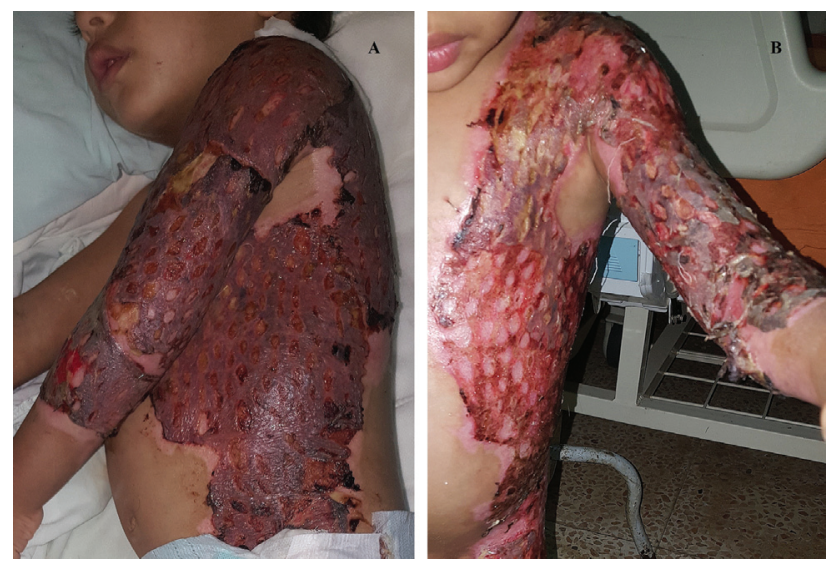

Fig. 4 Male patient, 8 years old, with deep dermal scald burn covered by gamma-irradiated homograft from father. (A) The allergic signs of rejection as cyanosed of skin undersurface started to appear after 15 days from coverage with delayed and minimal reactions. (B) Healing of burned area under irradiated homograft surface was observed after 19 days from coverage. 

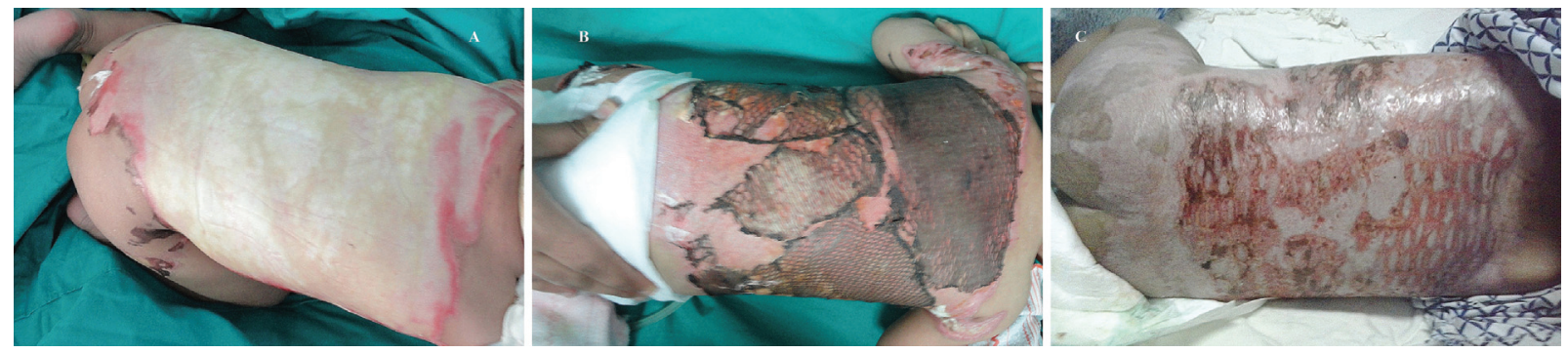

Fig. 5 Female patient, 2.5 years old, with deep dermal scald burn covered by irradiated homograft from father. (A) Eschar tissues all over the burned areas on the fourth day of injury. (B) The signs of rejection as skin discoloration and redness with granulation under surface burn areas. (C) Healing of burned area after complete homograft rejection at day 14 from coverage.

burns in whom homografts were exposed to a $25 \mathrm{kGy}$ dose of radiation. ${ }^{19}$

In our study, we used a tomotherapy device to deliver a 500 cGy radiation to a skin homograft in a single exposure. We found a significant difference in the results with an irradiated homograft in terms of percentage of rejection, healing, and need for autografting (- Figs. 3, 4, and 5).

According to Naoum et al, homograft application for extensive burns can improve patient outcomes while reducing length of hospital stay. ${ }^{20}$ Khoo et al concluded that burn coverage with homografts can promote angiogenesis with enhanced capillary ingrowth, provide growth factors and cytokines that cause chemotaxis and proliferation as a part of the inoculation process, and act similarly to an autologous skin graft. This incorporation occurs at the dermal collagenous matrix level. ${ }^{3}$

Local radiotherapy of the skin homograft reduces its ability to initiate immunological and inflammatory reactions, resulting in less inflammation and facilitating insidious creeping replacement of the homograft epidermis by native epithelium. In our study, the most significant fluctuation in the levels of laboratory parameters, including ESR, CRP, IL-6, and TNF, showed a significant decrease with the application of an irradiated homograft. Thus, we can assume that these parameters can be used as tools to predict the results and prognosis of such a treatment.

Our study has some limitations, including the large number of variables with a small number of patients. As a result, we were not able to develop a solid prognostic index. Thus, further studies of changes occurring in the immunological and inflammatory mediators of burn patients during management are required.

\section{Conclusions}

The exposure of skin homografts from related living donors to a local low dose of radiotherapy can reduce a graft's ability to initiate inflammatory and immunological reactions, thereby minimizing rejection of a graft and enhancing epithelialization in children with deep second- and third-degree burns. More multicenter studies are needed in the future to recommend this technique as a safe routine procedure.

Funding

None.

\section{Conflict of Interest}

The authors declare no conflict of interest.

\section{References}

1 Association AB. National Burn Repository. 2019 Report Version 14.0,Chicago, IL: American Burn Association; 2019

2 Singer AJ, Boyce ST. Burn wound healing and tissue engineering. J Burn Care Res 2017;38(03):e605-e613

3 Khoo TL, Halim AS, Saad AZ, Dorai AA. The application of glycerolpreserved skin allograft in the treatment of burn injuries: an analysis based on indications. Burns 2010;36(06):897-904

4 Abdullahi A, Amini-Nik S, Jeschke MG. Animal models in burn research. Cell Mol Life Sci 2014;71(17):3241-3255

5 Shevchenko RV, James SL, James SE. A review of tissue-engineered skin bioconstructs available for skin reconstruction. J R Soc Interface 2010;7(43):229-258

6 Nguyen LN, Nguyen TG. Characteristics and outcomes of multiple organ dysfunction syndrome among severe-burn patients. Burns 2009;35(07):937-941

7 Falanga V. Wound bed preparation: future approaches. Ostomy Wound Manage 2003;49(5A, Suppl)30-33

8 Rab M, Koller R, Ruzicka M, et al. Should dermal scald burns in children be covered with autologous skin grafts or with allogeneic cultivated keratinocytes?-“The Viennese concept" Burns 2005;31 (05):578-586

9 Seneschal J, Clark RA, Gehad A, Baecher-Allan CM, Kupper TS. Human epidermal Langerhans cells maintain immune homeostasis in skin by activating skin resident regulatory $\mathrm{T}$ cells. Immunity 2012;36(05):873-884

10 Mackay LK, Stock AT, Ma JZ, et al. Long-lived epithelial immunity by tissue-resident memory T (TRM) cells in the absence of persisting local antigen presentation. Proc Natl Acad Sci U S A 2012;109(18):7037-7042

11 Benichou G, Yamada Y, Yun SH, Lin C, Fray M, Tocco G. Immune recognition and rejection of allogeneic skin grafts. Immunotherapy 2011;3(06):757-770

12 Tiwari VK. Burn wound: how it differs from other wounds? Indian J Plast Surg 2012;45(02):364-373

13 Bhatia VY, Mishra S, Menon PA, Nanavati N. Life threatening deep scald burns in a neonate: A rare case report. Indian J Plast Surg 2013;46(01):130-133

14 Parment K, Zetterberg A, Ernerudh J, Bakteman K, Steinwall I, Sjoberg F. Long-term immunosuppression in burned patients assessed by in vitro neutrophil oxidative burst (Phagoburst). Burns 2007;33(07):865-871

15 Cheuk S, Wikén M, Blomqvist L, et al. Epidermal Th22 and Tc17 cells form a localized disease memory in clinically healed psoriasis. J Immunol 2014;192(07):3111-3120

16 Mrázová H, Koller J, Fujeríková G, Babál P. Structural changes of skin and amnion grafts for transplantation purposes following different doses of irradiation. Cell Tissue Bank 2014;15(03): 429-433 
86 Skin Homograft Rejection in Deep Burned Children Megahed et al.

17 Kearney JN. Quality issues in skin banking: a review. Burns 1998; 24(04):299-305

18 Guerrero L, Camacho B. Comparison of different skin preservation methods with gamma irradiation. Burns 2017;43(04):804-811

19 Mahdavi-Mazdeh M, Nozary Heshmati B, Tavakoli SA, Ayaz M, Azmoudeh Ardalan F, Momeni M. Human split-thickness skin allograft: skin substitute in the treatment of burn. Int J Organ Transplant Med 2013;4(03):96-101

20 Naoum JJ, Roehl KR, Wolf SE, Herndon DN. The use of homograft compared to topical antimicrobial therapy in the treatment of second-degree burns of more than $40 \%$ total body surface area. Burns 2004;30(06):548-551 